\title{
EFFECT OF HEAT TREATMENT ON MICROSTRUCTURAL CHANGES IN ALUMINIUM BRONZE
}

This paper attempts to summarise the microstructural changes which take place in aluminium bronzes during heat treatment. Another objective of this study was to map the potential of a certain type of aluminium bronzes for undergoing martensitic transformation. The methods, which were chosen for assessing the results of heat treatment with regard to their availability, included measurement of hardness and observation of microstructure using light and scanning electron microscopy, Additional tools for evaluation of microstructure comprised measurement of microhardness and chemical analysis by EDS. An important part of the experiment is observation of microstructural changes in the Jominy bar during the end-quench test. Upon completing experiments of this kind, one can define the heat treatment conditions necessary for obtaining optimum properties. In addition, the paper presents important findings on how to improve the corrosion resistance of aluminium bronzes by special heat treatment sequences.

Keywords: Aluminium bronzes, Heat treatment, Microstructure, EDS, Corrosion resistance

\section{Heat treatment of aluminium bronzes}

The techniques of heat treatment of aluminium bronzes comprise two groups, which are selected in dependence on the chemical and structural composition of the alloy to be treated:

- Heat treatment of single-phase alloys (up to approx. $9 \% \mathrm{Al}$ )

- Heat treatment of multiphase alloys $(\alpha+\beta)$, (approx. 9 to $14 \% \mathrm{Al})$

\subsection{Heat treatment of $\alpha+\beta$ (g2) alloys}

Above $570{ }^{\circ} \mathrm{C}$, the microstructures of alloys with 9.3 to $12 \%$ aluminium consist of two phases with varying proportions of $\alpha$ and $\beta$ grains. At temperatures below $565^{\circ} \mathrm{C}$, the $\beta$ phase decomposes into a eutectoid consisting of $\alpha$ and $\gamma 2$ phases. This pearlite-like structure forms only at cooling rates of less than $1{ }^{\circ}$ C.min-1. [1]

At higher cooling rates, the $\beta \rightarrow \alpha+\gamma 2$ transformation does not occur because the $\beta$ phase transforms to b1 with ordered cubic lattice at approximately $500{ }^{\circ} \mathrm{C}$. At very high cooling rates, these alloys may undergo diffusionless martensitic transformation, producing the $\beta^{\prime}$ phase, a supersaturated disordered solid solution. It is described as martensite and has face centred cubic structure. The microstructure of $\beta^{\prime}$ martensite consists of needles which are irregular on microscopic scale.

\section{Experimental programme}

\subsection{Experimental material}

The experimental material selected for the study of heat treatment of aluminium bronzes was the CuAl10Fe3Mn1.5 alloy.

The aluminium bronze was supplied in the form of $40 \mathrm{~mm}$-diameter rolled bars. 20 specimens for heat treatment were obtained by sectioning into cylinders with a height of approximately $15 \mathrm{~mm}$.

\subsection{Heat treatment}

The heat treatment experiments were designed to encompass a wide range of heat treatment schedules for the alloy in question and, where relevant, some undesirable treatment conditions as well. They were based on temperatures recommended in the alloy's data sheet and, in addition, included a reduced quenching (solutionizing) temperature of $700{ }^{\circ} \mathrm{C}$. Effects of the cooling rate on the

Chemical composition of experimental material

\begin{tabular}{|c|c|c|c|c|c|c|c|c|c|}
\hline \multicolumn{10}{|c|}{ Chemical composition [\%] } \\
\hline \multirow{2}{*}{ Specimen supplied } & & $\mathrm{Al}$ & $\mathrm{Fe}$ & $\mathrm{Mn}$ & $\mathrm{Pb}$ & $\mathrm{Sn}$ & $\mathrm{P}$ & $\mathrm{Ni}$ & $\mathrm{Zn}$ \\
\hline & 1st sampling & 9.67 & 3.46 & 1.31 & 0.003 & 0.021 & 0.001 & 0.081 & 0.024 \\
\hline
\end{tabular}

\footnotetext{
* UNIVERSITY OF WEST BOHEMIA,FACULTY OF MATERIALS SCIENCE AND METALLURGY, UNIVERZITNI 8, 306 14 PLZEN, CZECH REPUBLIC

** SILESIAN UNIVERSITY OF TECHNOLOGY, INSTITUTE OF ENGINEERING MATERIALS AND BIOMATERIALS, 18 A KONARSKIEGO STR., 44-100 GLIWICE, POLAND

* Corresponding author: hajek@kmm.zcu.cz
} 
microstructure and mechanical properties were mapped by the use of four different cooling environments - water, oil, air and furnace. The specimens were heated in a laboratory electrical furnace without any protective atmosphere. When the specimens were placed in the furnace, the furnace chamber had ambient temperature. Heating to $1000{ }^{\circ} \mathrm{C}$ took 90 minutes. Heating to $850{ }^{\circ} \mathrm{C}$ took place in 75 minutes and the $700{ }^{\circ} \mathrm{C}$ temperature was reached in 60 minutes. The holding time of 90 minutes at the "annealing" temperature was the same for all specimens.

TABLE 2

Designations of specimens

\begin{tabular}{|c|c|c|c|c|}
\hline \hline \multirow{2}{*}{ Temperature $/{ }^{\circ} \mathrm{C} /$} & \multicolumn{4}{|c|}{ Cooling environment } \\
\cline { 2 - 5 } & Water & Oil & Air & Furnace \\
\hline 1000 & $1(13-20)$ & 2 & 3 & 4 \\
\hline 850 & 5 & 6 & 7 & 8 \\
\hline 700 & 9 & 10 & 11 & 12 \\
\hline
\end{tabular}

\subsection{Light Microscopy Examination}

All samples were prepared by mechanical polishing and etched by Beraha reagent.

\section{Cooling in Water}

The resulting microstructure of specimens cooled in water depends on the heating temperature and time. After cooling from the highest heating temperature used $\left(1000^{\circ} \mathrm{C}\right)$, the resulting microstructure consists predominantly of martensite with a small amount of needles of the $\alpha$ phase. Fig. 1 (left) shows its appearance. Along coarse martensite plates, there are jagged oblong irregularly-distributed particles which were not attacked by the etchant. The martensite within the plates shows non-uniform deformation. The $\kappa_{\mathrm{IV}}$ precipitates [3] are uniformly distributed as small particles with a size of less than $1 \mu \mathrm{m}$.
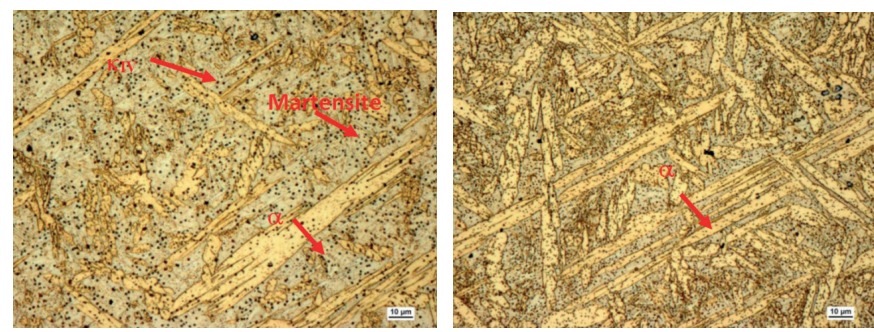

Fig. 1 Microstructure of samples heated for $90 \mathrm{~min}$ at $1000{ }^{\circ} \mathrm{C}$, cooled in water (left) and oil (right)

Upon heating to $850{ }^{\circ} \mathrm{C}$, the transformation to $\beta$ solid solution is not finished any more. The polyhedral grains of this phase represent approximately one third volume fraction. After cooling in water, some grains contain visible annealing twins. The spaces between grains are filled with small oblong $\alpha$ particles, as well as with proeutectoid $\alpha$ and $\beta^{\prime}$ martensite (Fig. 2 left). The $\kappa_{\mathrm{IV}}$ precipitates are larger. At the lower heating temperature $\left(700{ }^{\circ} \mathrm{C}\right)$, the extent of the eutectoid transformation $\beta$ becomes smaller, i.e. the fraction of the $\alpha$ phase in the microstructure increases, to approximately $70 \%$.
The polyhedral grains of the $\alpha$ solid solution are characterised by larger amounts of annealing twins.

\section{Cooling in Oil}

Cooling from the highest heating temperature $\left(1000{ }^{\circ} \mathrm{C}\right)$ in oil produces acicular microstructures, as in the previous case. However, these contain larger fractions of the acicular $\alpha$ phase. Between these needles, there is martensite, as well as elongated $\alpha$ particles. There are more $\kappa_{\mathrm{IV}}$ precipitates here than in the water-cooled specimens.

The fraction of the $\alpha$ solid solution upon cooling in oil from $850{ }^{\circ} \mathrm{C}$ remains constant. Grains, however, are coarser and some contain annealing twins. Along their indistinct boundaries, there are very fine globular precipitates. These are likely to be the $\kappa_{\mathrm{IV}}$ precipitates. The spaces between $\alpha$ grains are filled with fine $\kappa_{\mathrm{IV}}$ precipitates. There are coarse $\kappa_{\mathrm{I}}$ precipitates [3].

There is little difference between the fractions of $\alpha$ solid solution after cooling in oil from $700{ }^{\circ} \mathrm{C}$ and after cooling in water from $700{ }^{\circ} \mathrm{C}$. The grains contain increased amounts of annealing twins.

\section{Cooling in Air}

After cooling from $1000^{\circ} \mathrm{C}$, the microstructure resembles Widmannstätten structure. In these specimens, the fraction of the proeutectoid $\alpha$ phase is higher than in the specimens cooled in the previous media. The microstructure contains large numbers of $\kappa_{\mathrm{I}}$ and $\kappa_{\mathrm{IV}}$ precipitates.

Changes in the microstructure after cooling from $850^{\circ} \mathrm{C}$ can be seen clearly. The fraction of the $\alpha$ phase increases. The grains are polyhedral, unlike in the water-cooled specimens.

There are appreciable changes in the microstructure upon cooling from $700{ }^{\circ} \mathrm{C}$. The fraction of the $\alpha$ phase increases. The spaces between polyhedral grains begin to resemble a discontinuous network. The grains contain annealing twins, as well as globular particles of $\kappa_{\mathrm{I}}$ precipitate.
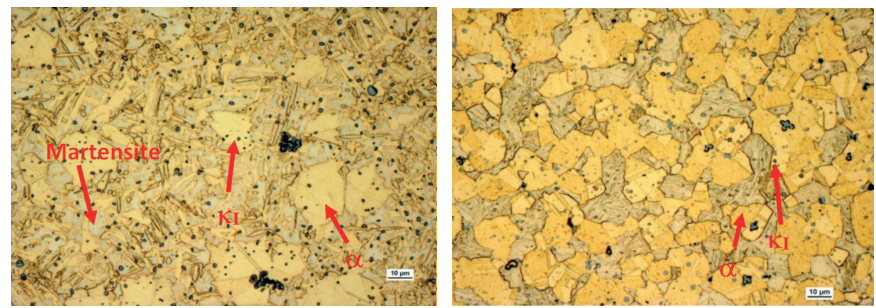

Fig. 2 Microstructure of samples heated fo Cooling in Furnace

The greatest change can be seen in the microstructure after cooling from $1000{ }^{\circ} \mathrm{C}$. After cooling from $1000{ }^{\circ} \mathrm{C}$, the microstructure resembles coarse Widmannstätten structure. In these specimens, the fraction of the proeutectoid $\alpha$ phase is higher than in the specimens cooled in the previous media. The microstructure contains large numbers of $\kappa_{\mathrm{I}}$ and $\kappa_{\text {IV }}$ precipitates. The coarse grains of the $\alpha$ solid solution are rounded. The grain interior is attacked more severely by the etchant (Fig. 3 right). The material contains the largest $\kappa_{I}$ precipitates, which are rich in iron and begin to take shape of rosettes. The space between grains contains elongated $\alpha$ particles and products of the eutectoid decomposition of the $\beta$ phase. 
The heating temperature of $850^{\circ} \mathrm{C}$ changes the nature of the microstructure. Polyhedral grains contain annealing twins. Their interiors are not attacked by the etchant to any different extent. The colour of the discontinuous network suggests that there is increased iron content. Inside the grains, there are coarse globular $\kappa_{\mathrm{IV}}$ precipitates. The iron-rich $\kappa_{\mathrm{I}}$ precipitates are distributed uniformly.

The microstructure after cooling from $700{ }^{\circ} \mathrm{C}$ is similar to the structure of the previous specimen. The differences are in finer $\alpha$ grains and individual particles between grains, instead of a network between grains.
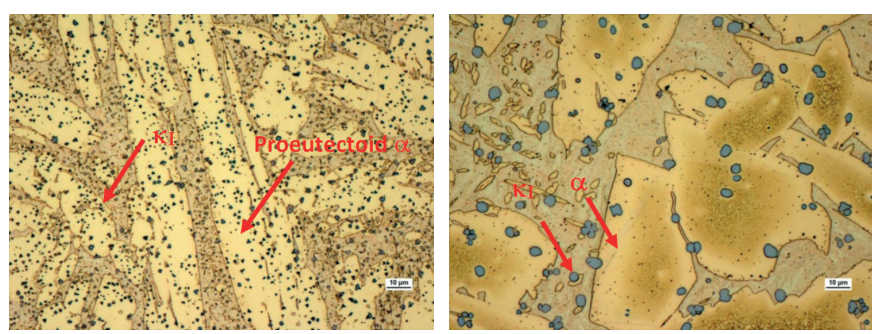

Fig. 3. Microstructure of samples heated for $90 \mathrm{~min}$ at $1000{ }^{\circ} \mathrm{C}$ air cooled (left) and cooled in furnace (right)

\subsection{EDS Analysis}

EDS analysis show that $\alpha$ phase has lower aluminium content (Fig. 4) than surrounding area. Eutectoid composition contains more of aluminium and iron. Composition of $\kappa_{\mathrm{I}}$ precipitate is inhomogenous (fig. 5).

\subsection{The Jominy end quench test:}

From a practical standpoint, hardenability data is important not only with regard to steels but also for aluminium bronzes. Hardenability is best described in terms of hardenability bands. For this reason, an experiment has been conducted which was equivalent to the end-quench hardenability test used for steels. Understandably, instead of the critical diameter, the information which was sought involved the dependence of hardness on the cooling rate. The quenching temperature was $900{ }^{\circ} \mathrm{C}$.
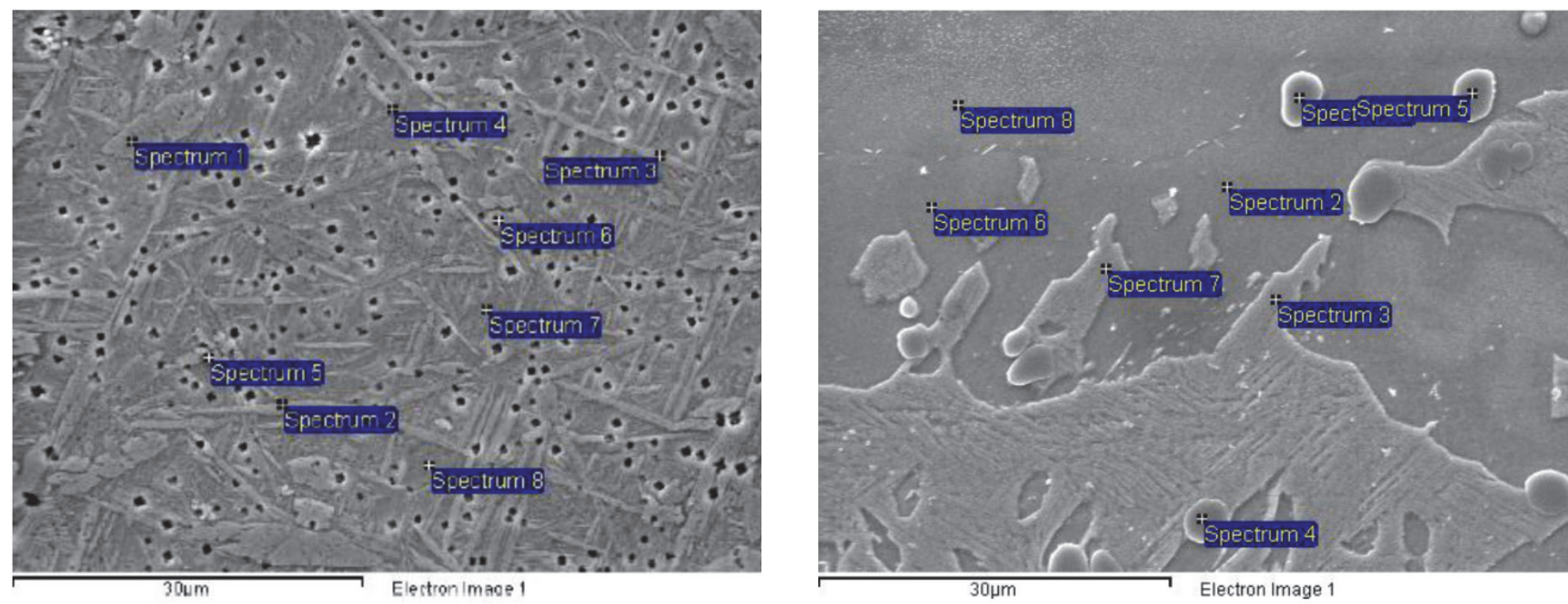

\begin{tabular}{|c|c|c|c|c|c|}
\hline & $\mathrm{Al}$ & $\mathrm{Mn}$ & $\mathrm{Fe}$ & $\mathrm{Cu}$ & Total \\
\hline Spectrum 1 & 9.09 & 1.21 & 2.25 & 87.45 & 100.00 \\
\hline Spectrum 2 & 11.02 & 1.28 & 2.76 & 84.93 & 100.00 \\
\hline Spectrum 3 & 10.36 & 1.52 & 2.85 & 85.27 & 100.00 \\
\hline Spectrum 4 & 11.38 & 1.19 & 1.67 & 85.76 & 100.00 \\
\hline Spectrum 5 & 9.56 & 1.39 & 1.53 & 87.52 & 100.00 \\
\hline Spectrum 6 & 9.82 & 1.40 & 1.81 & 86.97 & 100.00 \\
\hline Spectrum 7 & 9.50 & 1.22 & 4.08 & 85.20 & 100.00 \\
\hline Spectrum 8 & 9.64 & 1.80 & 2.01 & 86.54 & 100.00 \\
\hline \multicolumn{7}{|c|}{ All results in weight \% } \\
\hline
\end{tabular}

\begin{tabular}{|c|c|c|c|c|c|}
\hline & $\mathrm{Al}$ & $\mathrm{Si}$ & $\mathrm{Mn}$ & $\mathrm{Fe}$ & $\mathrm{Cu}$ \\
\hline Spectrum 1 & 11.43 & 2.1 & 3.13 & 73 & 10.39 \\
\hline Spectrum 2 & 9.79 & & 1.06 & 1.24 & 87.91 \\
\hline Spectrum 3 & 13.97 & & 1.82 & 0.77 & 83.44 \\
\hline Spectrum 4 & 10.78 & 2.39 & 2.69 & 74.5 & 9.66 \\
\hline Spectrum 5 & 10.12 & 2.47 & 2.55 & 78.3 & 6.57 \\
\hline Spectrum 6 & 10.57 & & 1.65 & 0.86 & 86.92 \\
\hline Spectrum 7 & 13.59 & & 1.57 & 0.94 & 83.9 \\
\hline Spectrum 8 & 8.39 & & 1.15 & 1.39 & 88.57 \\
\hline \multicolumn{7}{|c|}{ All results in weight \% } \\
\hline
\end{tabular}

Fig. 4. Results of EDS analysis at the specific points on samples heated for $90 \mathrm{~min}$ at $1000{ }^{\circ} \mathrm{C}$, cooled in water (left) and oil (right) 

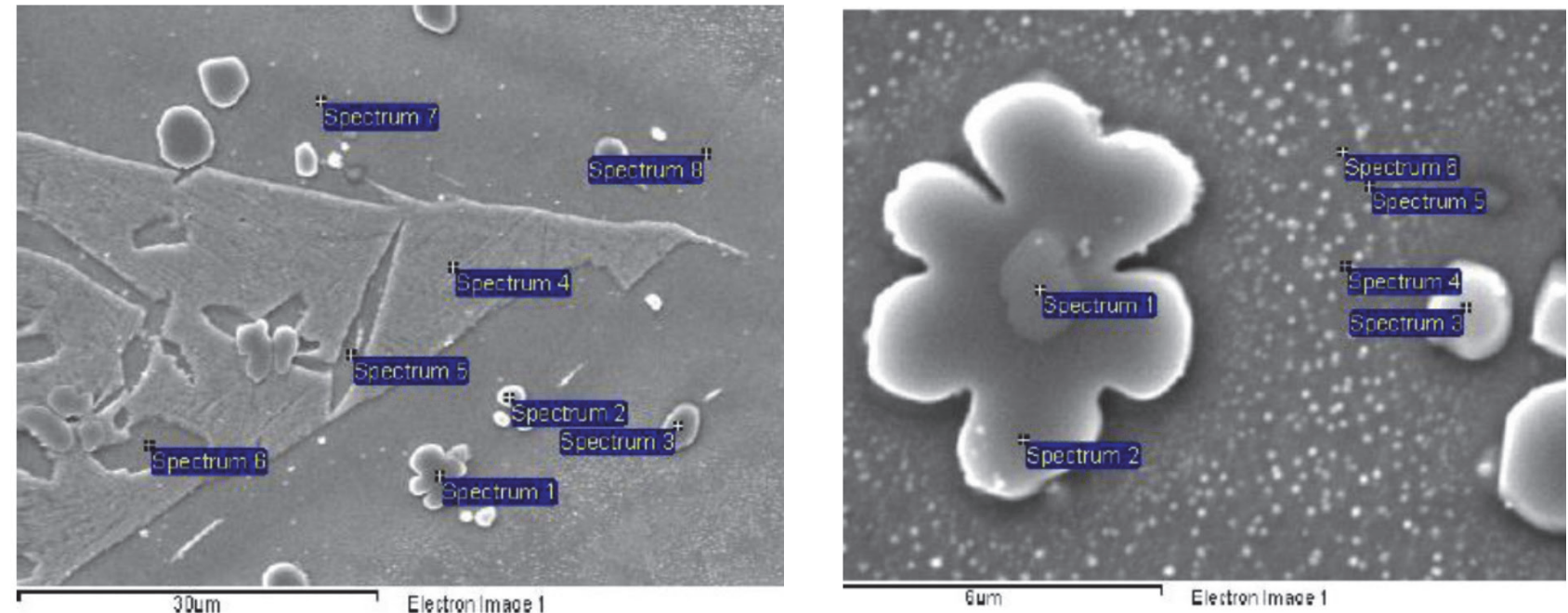

\begin{tabular}{|c|c|c|c|c|c|c|c|}
\hline & $\mathrm{Al}$ & $\mathrm{Si}$ & $\mathrm{Cr}$ & $\mathrm{Mn}$ & $\mathrm{Fe}$ & $\mathrm{Cu}$ & Total \\
\hline Spectrum 1 & 7.01 & 1.68 & 5.44 & 4.85 & 74.38 & 6.63 & 100 \\
\hline Spectrum 2 & 12.04 & 1.51 & & 2.52 & 50.39 & 33.34 & 100 \\
\hline Spectrum 3 & 10.35 & 2.51 & & 2.33 & 78.31 & 6.5 & 100 \\
\hline Spectrum 4 & 14.37 & & & 1.53 & 2.49 & 81.61 & 100 \\
\hline Spectrum 5 & 9.71 & & & 1.73 & 0.75 & 87.81 & 100 \\
\hline Spectrum 6 & 10.08 & & & 1.35 & 0.76 & 87.81 & 100 \\
\hline Spectrum 7 & 10.31 & & & 1.32 & 1.11 & 87.26 & 100 \\
\hline Spectrum 8 & 9.32 & & 1.75 & 0.55 & 88.37 & 100 \\
\hline \multicolumn{7}{|c|}{ All results in weight \% } \\
\hline \multicolumn{7}{|c|}{}
\end{tabular}

\begin{tabular}{|c|c|c|c|c|c|c|c|}
\hline & $\mathrm{Al}$ & $\mathrm{Si}$ & $\mathrm{Cr}$ & $\mathrm{Mn}$ & $\mathrm{Fe}$ & $\mathrm{Cu}$ & Total \\
\hline Spectrum 1 & 3.61 & 1.5 & 9.14 & 3.8 & 53.58 & 28.1 & 100 \\
\hline Spectrum 2 & 9.47 & 2.29 & & 2.35 & 77.63 & 8.26 & 100 \\
\hline Spectrum 3 & 11.8 & 2.74 & & 1.71 & 72.86 & 10.89 & 100 \\
\hline Spectrum 4 & 9.78 & & & 1.01 & 2.4 & 86.8 & 100 \\
\hline Spectrum 5 & 9 & & & 1.25 & 3.25 & 86.51 & 100 \\
\hline Spectrum 6 & 8.93 & & & 1.16 & 2.61 & 87.3 & 100 \\
\hline \multicolumn{8}{|c|}{ All results in weight \% } \\
\hline
\end{tabular}

Fig. 5 Results of EDS analysis at the specific points on samples heated for $90 \mathrm{~min}$ at $1000{ }^{\circ} \mathrm{C}$, cooled in furnace

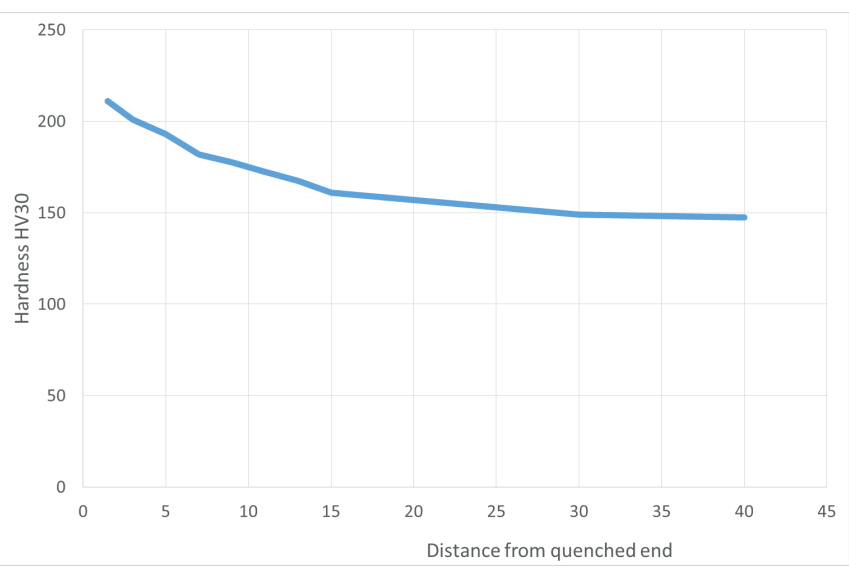

Fig. 6. Jominy curve for aluminium bronze

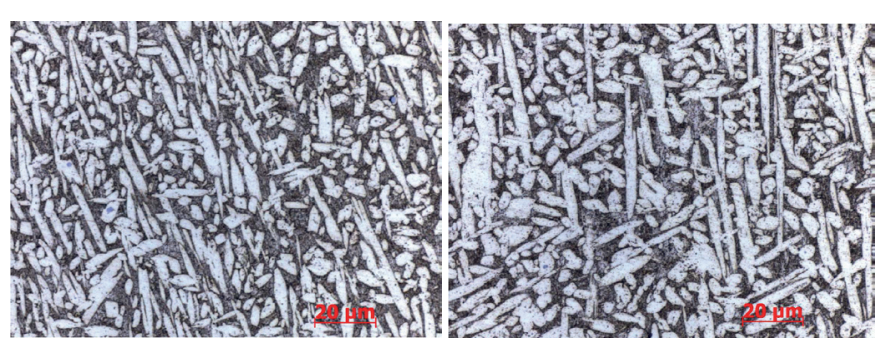

Fig. 7. Microstructure of the quenched end surface of the Jominy bar (left) and at $6 \mathrm{~mm}$ from the quenched end (right)

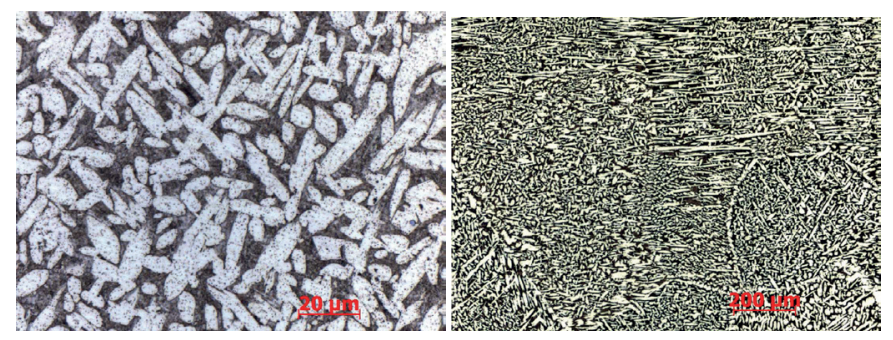

Fig. 8. Microstructure of locations at $12 \mathrm{~mm}$ (left) and $35 \mathrm{~mm}$ (right) distances from the quenched end

The microstructure of specimens taken from the quenched end of the Jominy bar contains predominantly plate martensite and proeutectoid $\alpha$-phase. The proeutectoid phase takes the form of needles. Polyhedral grains are in the minority. The micrograph shows the uniform distribution of $\kappa_{\mathrm{IV}}$ precipitates with the size of less than $1 \mu \mathrm{m}$. The hardness of this microstructure is approximately 200-205 HV.

With increasing distance from the quenched end (between approximately 5 and $10 \mathrm{~mm}$ ), the fraction of needles of the proeutectoid phase diminishes in favour of its massive grains. The fraction of the martensitic $\beta^{\prime}$-phase remains virtually unchanged. The occurrence of $\kappa_{\mathrm{IV}}$-precipitates slightly increases. Their distribution is uniform. In this region, the hardness is between 190 and $170 \mathrm{HV}$. 
At the distance of $10 \mathrm{~mm}$ from the quenched end, the amount and morphology of martensite remains constant, the proeutectoid $\alpha$-phase needles become more rounded and thicker, and the fraction of massive polyhedral $\alpha$-grains increases. The microstructure contains larger amounts of $\kappa_{\mathrm{I}}$ and $\kappa_{\mathrm{IV}}$ precipitates. It appears that these particles coarsen with decreasing cooling rate. In this region, the hardness is between 155 and $170 \mathrm{HV}$.

In areas which are farther from the quenched end, hardness remains constant. In terms of structure, coarse Widmanstätten morphology occurs and a network forms on prior grain boundaries of the $\beta$-solid solution. The hardness levels do not decrease below approximately $145 \mathrm{HV}$

\subsection{Corrosion resistance}

An important characteristic of this type of bronzes is corrosion resistance. This property was determined using specimens taken from the heat-treated bronze samples. The purpose of this experiment was to identify a heat treatment sequence which leads to the highest possible corrosion resistance. Therefore, deep cryogenic cooling was incorporated in those heat treatment sequences. The tests were carried out using a BioLogic SP-150 potentiostat. The corrosion potential and corrosion rate in an environment of neutral $3.5 \% \mathrm{NaCl}$ solution were determined using the polarisation test with measurement against the saturated calomel electrode (SCE). The counter electrode was a platinum wire. The results for various heat treatment sequences are shown in Table 3.

Results of the corrosion resistance measurement suggest that incorporating deep freezing to $-185{ }^{\circ} \mathrm{C}$ in the manufacturing route slows down the corrosion rate of bronzes in the environment of $3.5 \% \mathrm{NaCl}$ solution. At the same, it is apparent that neither the tempering temperature nor the stage, at which deep freezing is applied, has any substantial impact on the corrosion rate.

\section{Discussion of results}

The course and the mechanism of phase transformations are rather complex. There is a certain analogy with heat treatment of steel but there are appreciable differences as well. The nomenclature of the heating temperature is neither simple, nor clearly defined. As aluminium bronzes are characterised by martensitic transformation, the term "quenching" temperature appears to be the first choice. However, the cooling in air and in furnace leads to lower cooling rates than the critical rate. By contrast, the term "annealing" temperatures is not appropriate when non-equilibrium microstructures are produced. By the same token, describing the use of heating as "solution annealing" (although the related processes do take place) does not seem quite appropriate either. As a result, various names can be used for these heating temperatures in the literature, depending on the application or the resulting microstructure.

The effect of the increased iron content above its solubility level in this aluminium bronze is evidenced by the microstructures. Iron may be present in the alloy either as part of solid solution in copper or as the solid solution of iron and copper, precipitating during cooling, or as inclusions which form during a metallurgical process. All three forms of iron were observed. The relative proportions of these forms depend on the heat treatment schedule, i.e. on the heating temperature and the cooling procedure. The largest amount of $\kappa_{\mathrm{IV}}$ precipitates form after heating to the highest temperature: $1000{ }^{\circ} \mathrm{C}$. The size of the precipitates increases with decreasing cooling rate. The largest globular $\kappa \mathrm{I}$ precipitates were found in specimens which cooled in the furnace. At lower heating temperatures, the amounts of precipitates are smaller due to the lower solubility.

The highest and the lowest hardness values were obtained after heating to $1000{ }^{\circ} \mathrm{C}$. This is the recommended upper limit of quenching temperatures. This temperature is near the solidus. Diffusion-based phenomena take place alongside intensive grain growth. The grain growth continues when proeutectoid $\alpha$ forms (during cooling, particularly in a furnace). It is manifested by the rounding of grain boundaries and by the chemical heterogeneity of the grains.

The maximum hardness value was found in the watercooled specimen. Its microstructure consisted of martensite and a small amount of needles of the $\alpha$ phase. Their morphology indicates that a complete transformation of $\alpha$ to $\beta$ took place during heating but the cooling rate did not prevent partial proeutectoid transformation of $\beta$ to $\alpha$. Therefore, grain refinement and an increase in the cooling rate could be used to achieve higher hardness levels.

The lower cooling efficiency of the other media causes an increase in the fraction of the proeutectoid $\alpha$ phase and a decrease in hardness. The morphology of the precipitated $\alpha$ phase ranges from needles through a coarse Widmannstätten structure to relatively round grains.

The recommended soft annealing temperature is between $650{ }^{\circ} \mathrm{C}$ and $750{ }^{\circ} \mathrm{C}$. After heating to $700{ }^{\circ} \mathrm{C}$ and cooling in furnace, the specimen hardness was $156 \mathrm{HV} 10$.

Corrosion rate vs. heat treatment sequence

\begin{tabular}{|c|c|c|c|c|}
\hline \hline \multicolumn{7}{|c|}{ Heat treatment sequence } & \\
\hline $\begin{array}{c}\text { Quenching temperature } \\
\text { in water quenching }\left[{ }^{\circ} \mathrm{C}\right]\end{array}$ & Tempering & Deep freezing & Tempering & \multirow{2}{*}{ Corrosion rate [micrometre/year] } \\
\cline { 2 - 5 } & {$\left[{ }^{\circ} \mathrm{C}\right]$} & {$\left[{ }^{\circ} \mathrm{C}\right]$} & {$\left[{ }^{\circ} \mathrm{C}\right]$} & $\mathbf{1 5}$ \\
\hline \multicolumn{7}{|c|}{ As received - soft-annealed } & $\mathrm{X}$ & $\mathbf{1 5}$ \\
\hline 900 & 600 & $\mathrm{X}$ & 185 & $\mathbf{1 1}$ \\
\hline 900 & 600 & -185 & 250 & $\mathbf{1 2}$ \\
\hline 900 & 600 & -185 & 600 & $\mathbf{1 1}$ \\
\hline 900 & $\mathrm{X}$ & -185 & & \\
\hline
\end{tabular}


The effect of the cooling rate (the cooling efficiency of the medium) is also apparent in the case of the recommended quenching temperature of $850{ }^{\circ} \mathrm{C}$. The lower hardness (than in the specimen quenched from $1000{ }^{\circ} \mathrm{C}$ ) of $202 \mathrm{HV} 10$ can be explained by the incomplete transformation of the $\alpha$ to $\beta$ phase during heating. When the specimen is quenched in oil, hardness decreases to $159 \mathrm{HV} 10$, which corresponds to the result of the equivalent treatment from $700{ }^{\circ} \mathrm{C}$. Examination of the metallographic section reveals coarsening (growth of polyhedral grains of the $\alpha$ phase), as well as an increase in the amount of $\alpha$ in the areas of the initial $\beta$ phase.

As mentioned above, heat treatment of aluminium bronze is somewhat analogical to heat treatment of steel. The fundamental difference lies in the type of the solid solution. In steels, interstitial solid solution is the key phase, whereas the aluminium bronze contains a substitutional solid solution. In the same way as TTT and CCT diagrams are used in heat treatment of steel, it would be appropriate to use diagrams of the $\beta$ phase decomposition to describe the behaviour of aluminium bronzes. One has to bear in mind, however, that any such diagram applies to a particular chemical composition, grain size and "quenching" temperature.

The difference between the solid solutions in steel and in aluminium bronze governs the difference in strengthening by martensitic transformation, where there is "only" an increase in hardness from $200 \mathrm{HV}$ ( $\alpha$ phase) to approx. 350 HV ( $\beta$ 'phase). The microstructure constituent with the highest hardness is the $\alpha+\gamma_{2}$ eutectoid. Its hardness is given not only by the content of the $\gamma_{2}-\mathrm{Cu}_{32} \mathrm{Al}_{19}$ intermediate phase but mainly by its morphology, as with pearlite in steel.

Results of the Jominy end-quench hardenability test indicate that the hardness and strength of the component vary between the component's surface and core. The difference between the surface and core strength levels is approximately $200 \mathrm{MPa}$. The major cause of the reduction in strength with decreasing cooling rate is the change in the proeutectoid $\alpha$-phase morphology. The changes in the cooling rate that occur at distances of less than $40 \mathrm{~mm}$ from the quenched end have practically no impact on the martensite morphology. Naturally, larger amounts of the $\kappa_{\mathrm{IV}}$ phase precipitate with decreasing cooling rate.

During deep cryogenic treatment, the structure becomes stabilized, more closely packed and stress-relieved. Other important phenomena, which take place in the process, include the removal of areas with increased density of lattice defects and changes in precipitate configuration towards greater uniformity. In general, the structure thus become more homogeneous. This homogeneity can be considered the primary cause of the improvement in the corrosion resistance of aluminium bronzes.

\section{Conclusions}

- Conditions of heat treatment involving martensitic transformation have been defined

- Hardenability testing of aluminium bronzes is accompanied by profound changes in their microstructure at distances of $20 \mathrm{~mm}$ and less from the quenched end.

- With decreasing cooling rate, the morphology of the proeutectoid $\alpha$-phase changes. With decreasing cooling rate, the fraction of needles diminishes and massive grains of this phase prevail.

- With decreasing cooling rate, the fraction of $\kappa \mathrm{I}$ and $\kappa \mathrm{IV}$ precipitates increases. In addition, these precipitates coarsen gradually.

- Incorporating deep cryogenic treatment improves the corrosion resistance of aluminium bronzes considerably.

- From the corrosion resistance perspective, the difference between the effects of deep cryogenic treatment before or after tempering is not decisive.

\section{Acknowledgement}

This paper draws on outcomes of the SGS - 2015 - 016 project "Analysis of Surfaces of Assemblies and Tools by Surface Integrity Method and Impacts on End-Use Properties". This publication was co-financed by the Ministry of Science and Higher Education of Poland as the statutory financial grant of the Faculty of Mechanical Engineering SUT.

\section{REFERENCES:}

[1] J.L. Dossett, G.E. Totten, ASM Handbook 4, Heat treating, ASM International, Ohio, (1991).

[2] A. Franc, Problematika navařování hliníkových bronzů na ocel 15241, Diploma thesis, Západočeská Univerzita v Plzni, June (2005).

[3] E.A. Culpan, G. Rose, J Mater Sci, 13, (8), 1647-1657 (1978).

[4] M.R. Saboktakin, K. Hossein, J Mater Process Tech 214, (8), 1524-1529 (2014).

[5] V. Anantapong, S. Uthaisangusk, A. Suranuntchai, A. Manonukul, Mater Design, 60, (1), 233-243 (2014).

[6] L. Hurtalová, E. Tillová, Manuf Tech 13, (1), 44-50, (2013).

[7] M. Greger, M. Widomská, Manuf Tech 11, (11), 17-22 (2011).

[8] T. Górecki, S. Król, M.Tokarski, J Inst of Met 20, (1), 24-32 (1978).

[9] T. Tański, K. Labisz, B. Krupińska, M. Krupiński, M. Król, R. Maniara, W. Borek, J Therm Anal Calorim. DOI 10.1007/ s10973-015-4871-y, (2015).

[10] http://www.cda.org.uk/megab2/corr_rs/pub83-al-bronzealloys-for-industry.pdf 